\title{
A Possible Port of Entry into the Eye of Dog during Erratic Canine Heartworm (Dirofilaria immitis) Parasitism
}

\author{
Mineo HAYASAKI ${ }^{1) * * *}$, Mikako UENO $^{2)}$, Hiroyasu EJIMA ${ }^{3)}$, Akira MUNAKATA ${ }^{4)}$ and Yukio TAMURA ${ }^{5)}$ \\ 1) School of Veterinary Medicine, Yamaguchi University, Yoshida, Yamaguchi 753-8515, Japan \\ ${ }^{2}$ School of Medicine, Teikyo University, Itabashi, Tokyo 173-8605, Japan \\ ${ }^{3)}$ Ejima Animal Hospital/Eye Care Center, 2-1344-2 Ogawa, Kodaira, Tokyo 187-0032, Japan \\ 4) Munakata Animal Hospital, 6-19-42 Shakujiidai, Nerima, Tokyo 177-0045, Japan \\ 5) Tamura Central Animal Hospital, 3-8-1 Johtoh, Maebashi, Gunma 371-0016, Japan
}

(Received 8 May 2012/Accepted 1 October 2012/Published online in J-STAGE 15 October 2012)

ABSTRACT. A dog was suspected of suffering from ectopic Dirofilaria immitis infection, because a large white nematode worm was detected in the anterior chamber of the left eye. A cylinder-shaped fibrin sac in the anterior chamber was found in the eye of the dog by slit lamp microscopy. After successful surgical removal of the worm, the corneal wound produced by the keratotomy healed in a short period. The worm was estimated to be extremely young, 5th-stage-immature male D. immitis, equivalent to a 90-120-day-old worm postinfection, by close morphological measurement and an experimental infection study. Thus, an immature worm can exhibit erratic parasitism in a host's eye. The fibrin sac was considered to be a trace of the invasion route, and the cornea may have been the port of entry into the anterior chamber of the eye in the erratic migration of D. immitis.

KEY WORDS: Dirofilaria immitis, erratic parasitism, eye, port of entry.

doi: 10.1292/jvms.12-0206; J. Vet. Med. Sci. 75(3): 355-359, 2013

Ectopic Dirofilaria immitis infections in the anterior chamber of a dog's eye are rare, although $D$. immitis has been detected in unusual locations $[1,2,18]$. At least 18 cases of erratic $D$. immitis infections into the eyes of dogs have been reported over the past 7 decades. There were 10 cases in 8 reports from Japan [4, 11-13, 16, 17, 21, 22] and 8 cases in 5 reports from North America $[3,19,23]$ and Australia $[15,20]$. However, these were all clinical reports, lacking an analysis of pathological and parasitological aspects of the migratory mechanism; therefore, the entry port into the eyes or the migratory route to the eye remained unknown. It is difficult to elucidate the mechanism of migratory behavior of the worm during erratic $D$. immitis infection in the anterior chamber of a dog's eye, because of the difficulty in performing close clinico-pathological examinations in clinical patients, and a lack of reports of experimental erratic infection of $D$. immitis. The present study was carried out to investigate the port of entry into the eye in erratic $D$. immitis infections.

A clinical canine case of erratic $D$. immitis infection was treated at our animal hospital. The left eye was irritable and photophobic, and a large white worm exhibited whipping and spinning movements in the anterior chamber of the eye. This dog showed a nebula with diffuse opacity and a mass

*Correspondence to: Hayasaki, M., School of Veterinary Medicine, Yamaguchi University, Yoshida, Yamaguchi 753-8515, Japan.

**Present AdDRESS: HayASAKI, M., 2-26-8 Wakaba, Tachikawa, Tokyo 190-0001, Japan.

e-mail: tachikawa_hayasaki@yahoo.co.jp

(C)2013 The Japanese Society of Veterinary Science of white residue in the anterior chamber (Fig. 1). The white residue was also clearly observed from a different angle (Fig. 2). The dog, reared in Tokyo, was a 4-year-old mixed breed male weighing $9 \mathrm{~kg}$ with no particular anamnesis, and had never received treatment or prophylactic drugs for dirofilarial infection. The worm wriggled more actively in terms of its whipping and shaking movements in the anterior chamber when a flashlight was shone on it.

Slit lamp microscopy examination of the dog demonstrated the formation of a cylinder-shaped fibrin sac and the perforation of the iris in the anterior chamber of the left eye (Figs. 1 and 2). In contrast, there were no abnormal findings in the vitreous chamber or the ocular fundus. A fluorescein dye test revealed no focal lesions on the corneal surface. This fibrin sac consisted of a large mass of fibrin precipitate (Fig. 2) and was connected from the center of the inner surface of the cornea to the outer corner of the iris; it was considered to have been formed by the host's non-specific immunemediated expulsion reaction against the invading immature worm. These findings indicate that the sac was a trace of the invasion route; therefore, the center of the cornea was considered to be the port of entry into the anterior chamber of the eye. In addition, the perforation of the iris may have enabled passage between the anterior and posterior chambers. Interestingly, the worm disappeared from the anterior chamber after the slit lamp microscopic examination, but reappeared in the anterior chamber the next day. These clinical findings indicated that the immature worm was highly sensitive to light and moved into the anterior chamber angle or the posterior chamber to try to evade the light.

Keratotomy was performed, under general anesthesia, to remove it. The corneal incision was closed without sutures after instilling oxytetracycline chloride eye ointment. The 

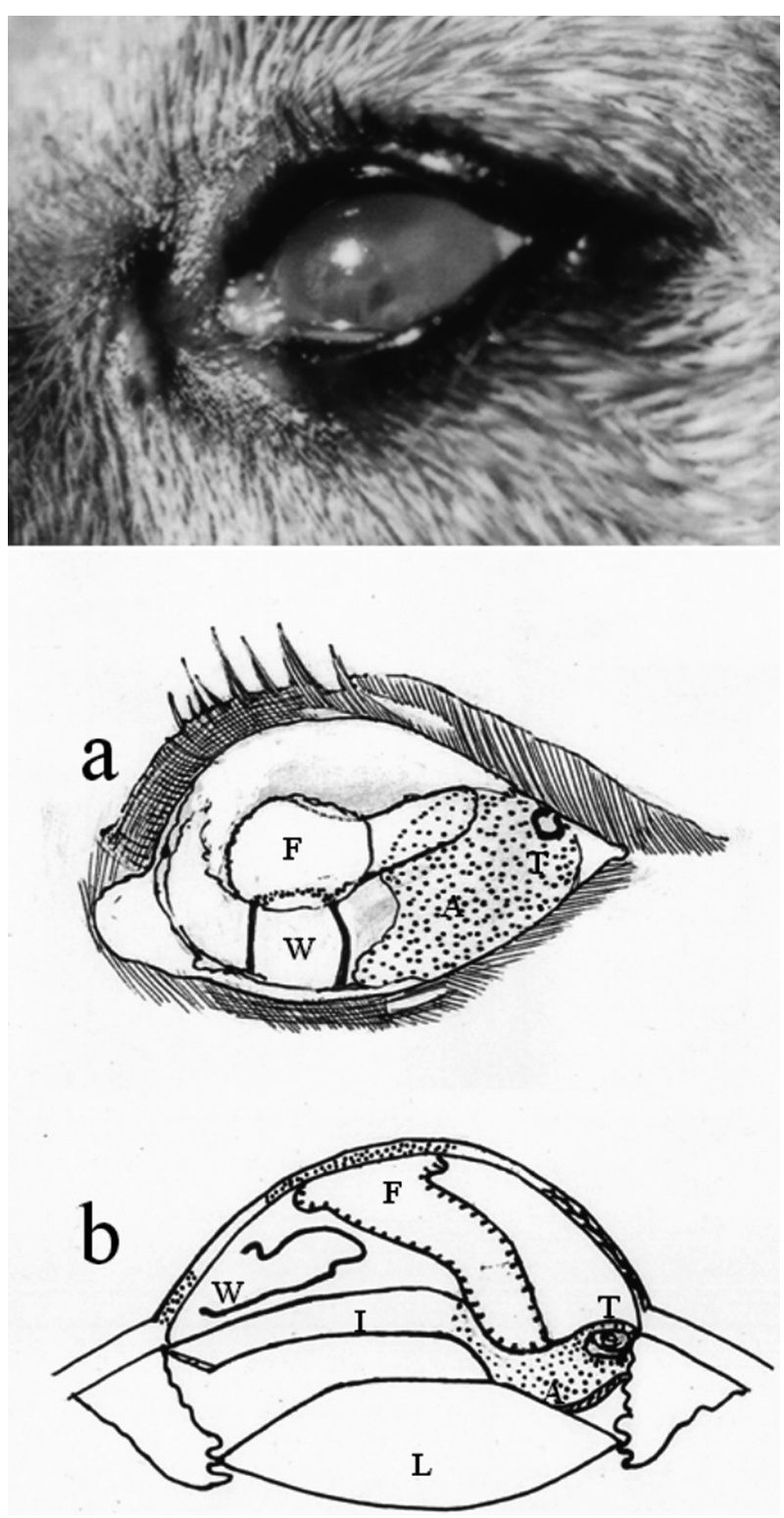

Fig. 1. Photograph and 2 diagrams indicating a possible port of entry into the anterior chamber of the left eye in dog 1. Diagrams show frontal (a) and cross-sectional (b) views. A: Adhesion between the lens and iris, F: Fibrin sac, I: Iris, L: Lens, T: Tresis in the iris, W: Worm.

gushing of aqueous fluid stopped spontaneously, and the bulging of the cornea recovered within $1 \mathrm{hr}$. The incised cornea healed within 4 days without any problems by employing an Elizabethan collar.

The aqueous humor of the dog was examined, showing slight changes, such as colorless, $\mathrm{pH} 7.6$, specific gravity 1.028 , protein level $3.4 \mathrm{~g} / \mathrm{d} l$, glucose level $75 \mathrm{mg} / \mathrm{d} l$, urea nitrogen (UN) level $15.1 \mathrm{mg} / \mathrm{d} l$ and RBC at $3 / \mu l$ and WBC at $8 / \mu l$. In contrast, the findings and mean values of 7 normal control dogs were colorless, $\mathrm{pH} 8.82$, specific gravity 1.007 ,
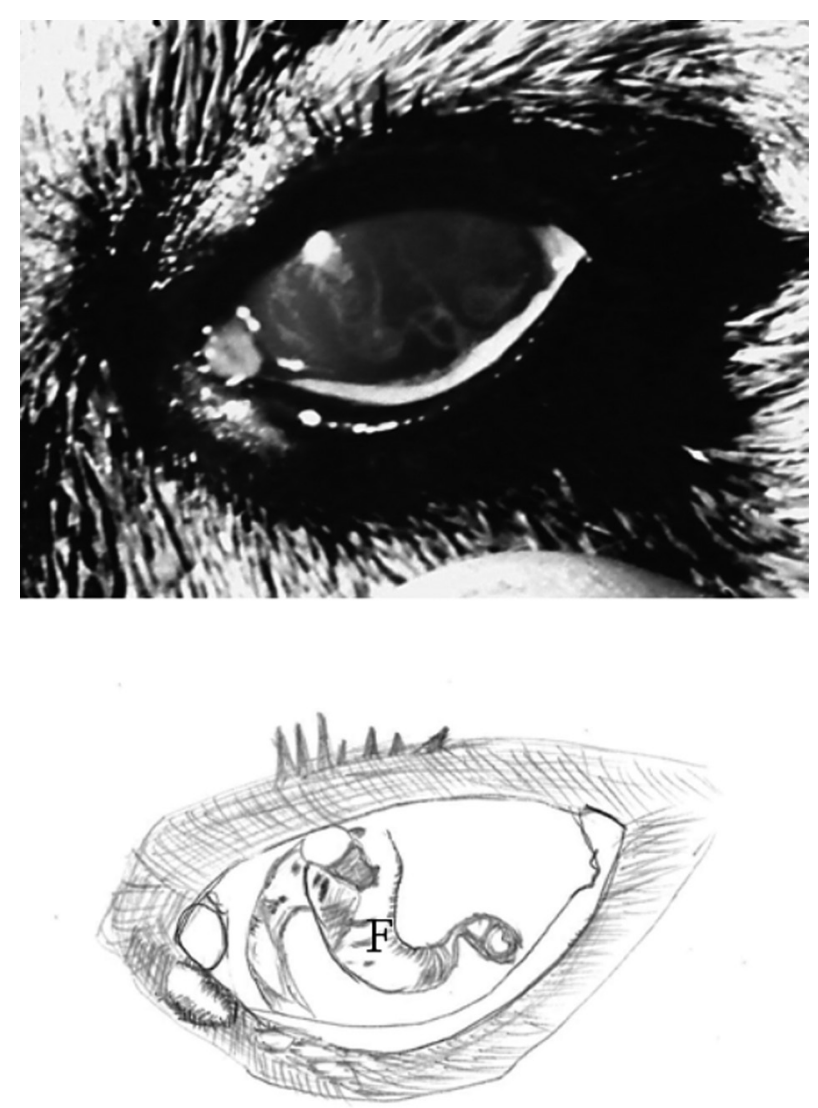

Fig. 2. Photograph and diagram of the left eye in dog 1 from a different angle, which revealed the fibrin sac in the anterior chamber. F: Fibrin sac

protein $0 \mathrm{~g} / \mathrm{d} l$, glucose $106.2 \mathrm{mg} / \mathrm{d} l$, UN $7.41 \mathrm{mg} / \mathrm{d} l$, and no $\mathrm{RBC}$ and WBC. These findings suggested that the worm released acidic and protein-derived metabolites, ingested glucose and slightly damaged ocular tissues in the anterior chamber.

Corneal wounds of the treated dog healed rapidly, within 4 days after the keratotomy. In comparison, the wounds of 10 dogs that underwent keratotomy operation for cataract healed within 3 days on average (Table 1). Because no lesion was observed on the surface of the cornea of the dog when the worm was found in the left eye, this suggested that, if a corneal wound is the entry port for a worm, the corneal wound may more rapidly heal after the immature worm had passed through it; therefore, it would be difficult to notice a corneal lesion.

The worm from the dog was morphologically identified as an immature adult male $D$. immitis of $7.5 \mathrm{~cm}$ body length (Table 2). The head was a round, and the mouth was a simple hole without lips or other organs. The mouth led directly into the esophagus, without a buccal cavity, and the esophagus did not possess the bulges and constrictions. Two spicules were an unequal length. To estimate the developmental age of the worm, an experimental D. immitis infection study was performed as previously described [10]. Eleven healthy 
Table 1. Healing of the corneal wound after keratotomy

\begin{tabular}{|c|c|c|c|c|c|c|c|c|}
\hline Dog & Breed & Sex & Age & $\begin{array}{l}\text { Weight } \\
(\mathrm{kg})\end{array}$ & $\begin{array}{c}\text { Aim of } \\
\text { keratotomy }\end{array}$ & $\begin{array}{l}\text { Operation } \\
\text { time } \\
(\min )\end{array}$ & $\begin{array}{c}\text { Duration (days) until } \\
\text { corneal coaptation } \\
\text { after the operation }\end{array}$ & Sequela \\
\hline 1 & Shiba Inu & Female & 8 & 13 & Cataract & 30 & 3 & None \\
\hline 2 & French Bull & Female & 2 & 9 & Cataract & 40 & 2 & None \\
\hline 3 & Cavalier & Male & 6 & 7 & Cataract & 35 & 1 & None \\
\hline 4 & Jack Russell & Female & 5 & 6 & Cataract & 35 & 4 & None \\
\hline 5 & Chihuahua & Male & 12 & 2 & Cataract & 40 & 3 & None \\
\hline 6 & Shiba Inu & Female & 7 & 9 & Cataract & 45 & 5 & None \\
\hline 7 & Toy Poodle & Male & 5 & 4 & Cataract & 35 & 2 & None \\
\hline 8 & Toy Poodle & Male & 7 & 4 & Cataract & 30 & 4 & None \\
\hline 9 & Bishon Frisé & Female & 3 & 5 & Cataract & 40 & 3 & None \\
\hline \multirow[t]{2}{*}{10} & Toy Poodle & Female & 2 & 4 & Cataract & 35 & 2 & None \\
\hline & & & & & & & Ave. 2.9 & \\
\hline
\end{tabular}

Table 2. Comparison of morphological measurements among the worm from dog 1, and immature and adult Dirofilaria immitis

\begin{tabular}{|c|c|c|c|c|c|}
\hline \multirow{3}{*}{$\begin{array}{l}\text { Worm (s) examined } \\
\text { Sex of worm }\end{array}$} & \multicolumn{5}{|c|}{ D. immitis } \\
\hline & \multirow{2}{*}{$\begin{array}{c}\begin{array}{c}\text { Worm from } \\
\left.\text { present case } 1^{a}\right)\end{array} \\
\text { Male }\end{array}$} & \multicolumn{2}{|c|}{$\begin{array}{l}\text { 113-day-old } \\
\text { immature worms }\end{array}$} & \multicolumn{2}{|c|}{ Adult worms ${ }^{\mathrm{c})}$} \\
\hline & & Male & Female & Male & Female \\
\hline No. of worms examined & 1 & 2 & 5 & 5 & 5 \\
\hline Length of body (mm) & 75 & $90 \pm 3$ & $112 \pm 11$ & $152 \pm 12.9$ & $309 \pm 1.9$ \\
\hline Width of body (mm) & 0.31 & $0.35 \pm 0.01$ & $0.36 \pm 0.01$ & $0.65 \pm 0.05$ & $1.09 \pm 0.05$ \\
\hline Nerve ring from anterior end $(\mu \mathrm{m})$ & 236 & $268 \pm 8$ & $285 \pm 12$ & $382 \pm 27$ & $405 \pm 25$ \\
\hline Cervical papillae from anterior end $(\mu \mathrm{m})$ & 535 & & & $697 \pm 29$ & $696 \pm 59$ \\
\hline Length of esophagus $(\mu \mathrm{m})$ & 1120 & $1033 \pm 8$ & $1181 \pm 69$ & $1199 \pm 157$ & $1508 \pm 89$ \\
\hline Vulva from anterior end $(\mu \mathrm{m})$ & & & $1741 \pm 285$ & & $3983 \pm 637$ \\
\hline Length of tail $(\mu \mathrm{m})$ & 111 & $105 \pm 2$ & $176 \pm 24$ & $104 \pm 7$ & $286 \pm 73$ \\
\hline \multicolumn{6}{|l|}{ Length of spicules $(\mu \mathrm{m})$} \\
\hline Left & 346 & $355 \pm 17$ & & $348 \pm 16$ & \\
\hline Right & 207 & $192 \pm 2$ & & $196 \pm 8$ & \\
\hline
\end{tabular}

a) Present dog case 1. b) These were collected from an experimentally infected dog on day 113 postinfection. c) These were collected from a naturally infected dog.

dogs, not infected with $D$. immitis, were experimentally infected with $D$. immitis, and the worms were then recovered at various intervals (144-322 days) postinfection after euthanasia, and their body lengths were measured (Table 3 ). In addition, close morphological measurements were performed on 113-day-old immature worms recovered from an experimentally infected dog and on adult worms recovered from a naturally infected dog (Table 2). The age of each worm is expressed as days postinfection. The experimental infection study indicated that the body length of the worm $(7.5 \mathrm{~cm})$ was much shorter than that of 144-day-old male worms $(12.5 ; 9.6-15.5 \mathrm{~cm})$ from the experimentally infected $\operatorname{dog}$ (Table 3), and was even shorter than that of 113-day-old male worms $(9.0 \pm 0.3 \mathrm{~cm})$ (Table 2). These results suggested that the worm was younger than 113 days old.

In the 18 clinical cases previously reported, all of the recovered worms were immature adult $D$. immitis. There were 5 males, 5 females and 8 with unidentified sex, and they were $4.4-12 \mathrm{~cm}$ in length. In the present study, as shown in
Table 2, the immature male worm $(7.5 \mathrm{~cm}$ in length) from the dog was found to be equivalent to an early phase of the 5th-stage-immature worm, younger than 113 days old and close to 90-120-day-old worms postinfection, just after the 4 th molt, which were $4-8 \mathrm{~cm}$ in length among males, as reported by Kume and Itagaki [14].

We previously demonstrated that 5th-stage juvenile worms of $D$. immitis retain the capacity for re-migration [6]. Briefly, live immature adult worms that were recovered from the pulmonary arteries of experimentally $D$. immitis-infected dogs 145-147 days postinfection were transplanted into the subcutaneous tissue of 6 anesthetized uninfected healthy dogs. Then, after 1 or 3 months, these worms had already reached and were recovered from the pulmonary arteries of these dogs. The recovery rate was $45.5 \%$. Thus, 5 th-stage juvenile worms retain the capacity for re-migration, at least until 145-147 days postinfection, even after they have reached the pulmonary arteries once as a final parasitic destination. From this finding, it can be considered that an 
Table 3. Comparison of the body lengths of Dirofilaria immitis collected at various ages from experimentally infected dogs

\begin{tabular}{|c|c|c|c|c|c|}
\hline \multirow[b]{3}{*}{$\begin{array}{l}\text { Age (Days) } \\
\text { after } \\
\text { infection }\end{array}$} & \multirow[b]{3}{*}{$\begin{array}{c}\begin{array}{c}\text { No. of } \\
\text { dogs } \\
\text { examined }\end{array}\end{array}$} & \multicolumn{4}{|c|}{ Length $(\mathrm{cm})$} \\
\hline & & \multicolumn{2}{|c|}{ Male } & \multicolumn{2}{|c|}{ Female } \\
\hline & & $\begin{array}{c}\text { No. of } \\
\text { worms } \\
\text { measured }\end{array}$ & $\begin{array}{c}\text { Mean } \\
\text { (Min-Max) }\end{array}$ & $\begin{array}{c}\text { No. of } \\
\text { worms } \\
\text { measured }\end{array}$ & $\begin{array}{c}\text { Mean } \\
\text { (Min-Max) }\end{array}$ \\
\hline 144 & 1 & 104 & $12.5(9.6-15.5)$ & 121 & $15.9(11.2-20.1)$ \\
\hline 152 & 2 & 27 & $13.2(11.9-17.3)$ & 32 & $16.2(9.1-20.2)$ \\
\hline 161 & 1 & 20 & $12.5(11.0-15.0)$ & 20 & $18.5(15.0-26.5)$ \\
\hline 194 & 2 & 14 & $15.2(13.3-16.3)$ & 17 & $21.8(16.9-25.2)$ \\
\hline 223 & 2 & 13 & $15.3(13.4-17.3)$ & 15 & $22.8(19.8-26.4)$ \\
\hline 253 & 2 & 37 & $11.4(9.5-14.0)$ & 40 & $19.8(15.5-25.0)$ \\
\hline 322 & 1 & 3 & $13.8(13.3-14.2)$ & 6 & $25.8(23.0-27.6)$ \\
\hline
\end{tabular}

immature worm can migrate as accidental or erratic parasitism into the eye of a host, if an early phase of a 5th-stage immature worm fails to migrate normally into the pulmonary arteries for some unknown reason.

Examination of the aqueous humor of the dog showed slight changes of a low $\mathrm{pH}$, low glucose concentration and slight bleeding inside the anterior chamber, suggesting that the invading worm, however, did not seriously damage the dog's eye. This may have been due to a high susceptibility of $D$. immitis to the dog as the definitive host.

In general, when $D$. immitis migrates between the organs/ tissues of a definitive host's body during its larval and 5thimmature-adult stages in normal growth, it causes essentially no or very slight histo-pathological damage in the intermediate locations, such as tissue necrosis or internal bleeding from small blood vessels. Additionally, in our research of many cases of experimental $D$. immitis infection, we have found no histological damage in these infected dogs, even though numerous infective larvae $\left(\mathrm{L}_{3}\right)$ of $D$. immitis were employed, that is, a mean number of 151.5 ( $\min 94-\max$ 457) $\mathrm{L}_{3}$ per dog [5,7-9], although, if an erratic infection occurs in an undefinitive host, it may cause severe tissue damage in the invaded organ. For example, larval Toxocara canis, a canine round worm, infects children, causing ophthalmitis and gnathostomiasis, as well as adults, causing creeping eruption as cutaneous and visceral larva migrans, because $T$. canis has a lower susceptibility to humans. These types of tissue and visceral damage should be produced by the immune-mediated inflammatory reaction of the host against the invading worm as a foreign body.

Regarding the migration route, two routes to the anterior chamber of the eye can be considered: the cranial-hypodermis route and the intracranial-optic foramen (foramen opticum) route, which have been proposed for a long period among specialists of clinico-parasitological research of dirofilariosis and filariosis. However, neither has been confirmed even by $D$. immitis experimental infection studies. Thus, the present study provided evidence of a possible port of entry in erratic migration into the eye, namely, the corneal route.

In the former, the worm may burrow through the subcutaneous areas of the face, reach the corner of the eye, pass through and then penetrate the surface of the cornea. In the latter, the worm may burrow through the surface of the brain, reach the optic foramen, pass through, then penetrate into the eyeball and appear in the anterior chamber. According to this hypothesis, an infected dog may show some degree of parasitic encephalitis and/or severe eye damage such as vision impairment, blindness, ophthalmitis, ophthalmalgia or internal ophthalmopathy including bleeding or necrosis of the ocular fundus, inducing pain, nervous system irritation or nerve disorder. However, the present dog showed only irritableness, nebula and photophobia. These findings indicate that the immature worm invaded the anterior chamber without stimulating the host's immune inflammatory response. The findings of the rapid healing of the cornea and formation of a fibrin sac in the anterior chamber of the eye suggest that the immature worm entered the cornea from the outside, without leaving any traces of tissue damage, pain, or leaking of the aqueous humor.

\section{REFERENCES}

1. Alicata, J. E. and Morrison, R. H. 1936. A note on the occurrence of the heartworm Dirofilaria immitis in the eye of a dog. N. Am. Vetern. 17: 41-42.

2. Beller, J. 1962. Parasite in the eye of a dog. Small Anim. Clin. 2: 681-683.

3. Brightman, A. H., Helper, L. C. and Todd, K. S. Jr. 1977. Heartworm in the anterior chamber of dog's eye. Vet. Med. Small Anim. Clin. 72: 1021-1023. [Medline]

4. Fujii, I., Hyohdoh, T., Kimura, K., Ibaraki, J., Kaneshiro, Y., Yamada, T., Munakata, S. and Ikeda, T. 1971. Ectopic infection of juvenile Dirofilaria immitis in the anterior chamber of eye of two dogs. J. Jpn. Vet. Med. Assoc. 24: 639 (in Japanese).

5. Hayasaki, M. 1982. Reaginic and hemagglutinating antibody production in dogs infected with Dirofilaria immitis. Jpn. J. Vet. Sci. 44: 63-70. [Medline] [CrossRef]

6. Hayasaki, M. 1996. Re-migration of fifth stage juvenile $D i$ rofilaria immitis into pulmonary arteries after subcutaneous transplantation in dogs, cats, rabbit. J. Parasitol. 82: 835-837. [Medline] [CrossRef]

7. Hayasaki, M., Nakagaki, K., Kobayashi, S. and Ohishi, I. 1981. Immunological response of dogs to Dirofilaria immitis infection. Jpn. J. Vet. Sci. 43: 909-914 (in Japanese with English summary, 
tables and figures). [Medline] [CrossRef]

8. Hayasaki, M. and Ohishi, I. 1989. Influence of immune treatments against Dirofilaria immitis infection in dogs. Jpn. J. Vet. Sci. 51: 540-546. [Medline] [CrossRef]

9. Hayasaki, M. and Ohishi, I. 1989. Influence of immune-suppressants against Dirofilaria immitis infection in dogs. Jpn. J. Vet. Sci. 51: 957-962.

10. Hayasaki, M. and Saeki, H. 2009. Inhibition and prevention efficacy against mosquito bloodsucking and Dirofilaria immitis infection by administration of topical insecticide. J. Vet. Med. Sci. 71: 1049-1052. [Medline] [CrossRef]

11. Horiba, T., Asakura, S., Katoh, K., Yamazaki, K. and Nakagawa, T. 1981. Clinical findings of Dirofilaria immitis in the anterior chamber of a dog. J. Jpn. Vet. Med. Assoc. 34(supplement): 88-89 (in Japanese).

12. Itoh, K. and Narama, I. 1981. Three clinical cases on ectopic infection with dirofilariosis. J. Jpn. Vet. Med. Assoc. 35(supplement): 58 (in Japanese).

13. Kore-eda, T., Yonemura, D., Shimizu, I., Tsuruno, Y. and Akaeda, M. 1972. Two clinical cases of ectopic infection of Dirofilaria immitis in the eye of dogs, in which one case developed a corneal cyst. J. Jpn. Vet. Med. Assoc. 25: 540 (in Japanese).

14. Kume, S. and Itagaki, S. 1955. On the life-cycle of Dirofilaria immitis in the dog as the final host. Br. Vet. J. 111: 16-24.

15. Lavers, D. W., Spratt, D. M. and Thomas, C. 1969. Dirofilaria immitis from the eye of a dog. Aust. Vet. J. 45: 284-286. [Med- line] [CrossRef]

16. Maruhashi, M., Hara, M., Kiyo-oka, T. and Taniguchi, M. 1975. Dirofilaria immitis in the anterior chamber of a dog's eye. In: Abstracts of the 80th Annual Meeting, Jpn. Vet. Med. Sci. 95 (in Japanese).

17. Nagoshi, H. and Yada, S. 1972. Clinical case of Dirofilaria immitis in the eye of a dog. J. Jpn. Vet. Med. Assoc. 25: 579 (in Japanese).

18. Otto, G. F. 1974. Occurrence of the heartworm in unusual locations and unusual hosts. pp.6-13. In: Proceeding of the Heartworm Symposium '74 (Morgan H. C. ed.). Vet. Med. Publ. In., Bonner Springs, Kansas.

19. Schnelle, G. B. and Jones, T. C. 1971. Dirofilaria immitis in the eye and in an interdigital cyst. J. Am. Vet. Med. Assoc. 107: $14-16$.

20. Spratt, D. M., Mallett, G., Derrington, P. C. and Thomas, C. 1971. Male Dirofilaria immitis from the eye of a dog. Aust. Vet. J. 47: 124. [Medline] [CrossRef]

21. Takeuchi, K. 1931. Case report of canine heartworm from the eye of a dog. Jpn. J. Oh-yoh Jyuigaku Zasshi 4: 16-17 (in Japanese).

22. Takeuchi, K. 1978. Clinical case of Dirofilaria immitis in the eye of a dog. J. Vet. Med. 109: 370-371 (in Japanese).

23. Thornton, J. G. 1978. Heartworm invasion of the canine eye. Mod. Vet. Pract. 59: 373-374. [Medline] 